\title{
REINFORCED WHITE FLOUR
}

\author{
By Dr. T. Moran and Prof. J. C. Drummond
}

$\mathrm{I}^{\mathrm{N}}$ the House of Commons on July 18, the Parliamentary Secretary to the Ministry of Food announced that very shortly the white loaf would be fortified with a supplement of vitamin $\mathrm{B}_{1}$ (aneurin) and a calcium salt. It is understood that the vitamin $B_{1}$ will add approximately 100 I.U. to the daily intake, whilst the addition of calcium will ensure that all classes of the population are receiving at least the daily requirement of approximately $0.60 \mathrm{gm}$. Both constituents will be introduced into the flour stream at the mill, where accurate control can easily be achieved. This decision will probably not satisfy the advocates of brown or wholemeal bread; but it is a compromise which is sound on nutritional grounds and inevitable from the practical point of view.

The present-day straight-run white flour (73 per cent extraction) has a $B_{1}$ content of 0.30 I.U. per gram against 0.75 and $1 \cdot 3$ for 85 per cent extraction and genuine (100 per cent) wholemeal, respectively. These are only average figures, since the amount in different wheats varies from about 0.6 I.U. to 3.3 I.U. per gram. Taking the average consumption at $60 \mathrm{oz}$. a week, white flour at present contributes approximately 80 I.U. a day; the new flour will increase the figure to 180 I.U.

Dietary surveys have established that the nation as a whole is not receiving sufficient $B_{1}$. The League of Nations Technical Commission on Nutrition gave the figure of 300 I.U. a day as the daily need of an adult male. There is now, however, considerable evidence to show that this figure is low and, excluding the particular case of pregnant women, the minimal requirement per weighted head of the population is $400-500$ I.U. per day. An analysis of Sir John Orr's 1936 survey shows that the intake of 50 per cent of the population falls below this figure, whilst a more recent survey gives the average per head figure as approximately 300 I.U. per day. The proposed supplement to white flour should, therefore, greatly reduce $B_{1}$ deficiency. Furthermore, such a step is particularly important at the present time when the deficiency is likely to be aggravated because of the possible reduction in the consumption of meat and dairy produce.

The decision to increase the calcium content of bread is of particular interest because floureither white or wholemeal-is not an important source of this mineral : on the basis of a requirement of $0.60 \mathrm{gm}$. per day, flour only contributes about 10 per cent of this amount. There is good evidence of calcium deficiency in many diets, and obviously flour is a convenient vehicle to make it good. The ratio of calcium to phosphorus in white or wholemeal flour is $1: 6 \frac{1}{2} 10$ and is, therefore, not well suited to the needs of the animal bodywhich are best met by foods with a ratio of $1-2: 1$. This is an argument against the addition of calcium phosphates, although they would, in fact, tend to correct the balance. One possibility is calcium carbonate which, introduced at the rate of $\frac{1}{2} \mathrm{lb}$. per sack (280 lb.) of flour, would raise the calcium intake of Orr's lowest income groups to roughly the minimal level. Incidentally, this quantity of calcium carbonate would have no adverse effect on the palatability or general quality of bread.

The introduction of the new white flour will undoubtedly stultify the controversy about white versus brown bread, since it is mainly in respect of $B_{1}$ that the white loaf has been open to attack. There is not the same evidence that we are deficient in vitamin $\mathrm{E}$ or the members of the $\mathrm{B}_{2}$ complex, which are present in wholemeal flower, while, as regards the mineral constituents, the relative merits of the two flours are uncertain because of the higher phytic acid content of wholemeal flour. The practical objections to wholemeal bread, however, are, at the moment, overriding. The evidence is that the bulk of the people prefer white bread ; it is certainly true that only 5-10 per cent of the bread sold is brown or wholemeal. Again, any increase in the extraction would reduce the amount of wheat offals available for feeding stuffs and, in particular, jeopardize our milk supplies. Finally, white flour keeps very much better than brown or wholemeal flour and need not be turned over so frequently. This is particularly important at the present time on account of the vast stocks of flour that are being stored as a war reserve. Nevertheless, Mr. Boothby made it clear that wholemeal bread will still be available to those who prefer it and at the same price as that for white bread.

The increased intake of $B_{1}$ should materially improve our general health. Beriberi is rare in Great Britain, but the effects of partial deficiency, including loss of appetite, physical vigour and disorders of the alimentary tract, the nervous 
system and cardiovascular system, must be widespread. It is always difficult to relate suboptimal health to the lack of a particular nutritional factor, but the recent direct experiments of Jolliffe in the United States are particularly striking. He gave a daily ration to five healthy subjects, containing only half the minimal dose of $\mathrm{B}_{1}$, and found that, within five days, four of the subjects showed characteristic signs of $B_{1}$ deficiency, including fatigue and lassitude, anorexia, precordial pain, burning of the feet, muscle cramps and palpitation. The introduction of an increased amount of aneurin into the diet caused all these symptoms to disappear within three days.

So much for the nutritional aspect. As regards the appearance and palatability of the new bread, careful tests have shown that aneurin is absolutely inert and has no effect on the dough, the volume of the loaf or the crumb character of the bread. Furthermore, due to the acid $p \mathrm{H}$ of flour, approximately $5 \cdot 4$, the aneurin is quite stable and there is no loss during doughing or baking. The flour will, therefore, be indistinguishable in appearance and handling properties from the present-day flour.

The introduction of the small amount of aneurin necessary will present no difficulty. It will be first mixed with a suitable quantity of flour, and this concentrate will be added at the rate of $1 \mathrm{oz}$. per sack. Equipment is in existence for doing this, and tests have already been made showing that there will be no difficulty in obtaining uniform distribution of the aneurin throughout each sack and in the entire flour stream. Determination of the aneurin in the flour and bread is possible by the thiochrome test with an accuracy of at least 4 per cent.

The new loaf, which has been under consideration for some time past by the milling industry and the Ministry of Food, now has the support of the Scientific Food Committee under the chairmanship of Sir William Bragg. Viewed from the general aspect of the nation's food, it is a revolutionary advance, because it can only mean that, in the future, whilst the preferences of the public will always receive first consideration, steps will be taken to make good any nutritional deficiencies both in individual foodstuffs and in our diet as a whole. The new loaf, in fact, with its supplement of vitamin $B_{1}$ on one hand and calcium on the other, embodies this general policy. There will now be two outstanding examples of fortified foodstuffs, bread and margarine-incidentally, both of first importance in the food of the poor.

\title{
PLANT DISEASE IN RELATION TO THE PUBLIC*
}

\author{
BY Prof. W. BRown, F.R.S., \\ Imperial College of Science and Technology
}

\begin{abstract}
7 'HE term 'plant disease' is used in somewhat different senses. As typical examples one would cite such troubles as rust, mildew, dampingoff of seedlings, etc., in which the higher plant is attacked by a parasitic fungus or similar plant organism. The destruction of fruit blossom by a late frost or the failure of a crop from drought or malnutrition are not commonly looked upon as the effects of disease ; but it is logical to extend the term to include such cases. This has been the practice in human pathology where, for example, a group of 'deficiency diseases' is well recognized. Similar troubles occur also in plants. One speaks, therefore, of the physiological as against the parasitic type of disease, a division which is convenient, though in practice it is not possible to draw a hard and fast line between them.
\end{abstract}

* From a Chadwick Public Lecture delivered on June 20.
Again, it is customary to distinguish between diseases and pests; for example, rose mildew is a disease, rose aphis is a pest. It is usual to apply the term 'pest' when the parasite is an animal, but again there are exceptions. Thus one speaks of the eelworm disease of narcissus, though the causal agent is an animal. The line of demarcation is distinct in theory, but pests and diseases are often interlinked, as in many virus diseases of plants.

For the present purpose, the effect on the crop is the matter of chief interest, and this may be the same whatever the causal agent-whether it be fungus, bacterium, virus, insect, nematode, etc., or whether the cause be strictly physiological. The effect may be sudden, leading to death of the plant at a very early stage, even before germination; or the plant may flourish for a long time and then be crippled or destroyed as it reaches 